\section{Too-Low Iron Doses and Too Many Dropouts in Negative Iron Trial?}

To THE EDITOR: We read with interest the article by Steensma et $\mathrm{al}^{1}$ in the January 1, 2011, issue of Journal of Clinical Oncology on the comparison of parenteral, oral, or no iron supplementation for patients who were treated with darbepoetin alfa for chemotherapyassociated anemia. The results contrast with those of six previously published $^{2-7}$ and two additionally reported ${ }^{8,9}$ clinical trials that showed a significant benefit and good tolerability of parenteral iron compared with oral or no iron supplementation in patients with cancer who were receiving a concomitant erythropoiesis-stimulating agent. We believe that the interpretation and understanding of the results of the study by Steensma et al might have been facilitated by reporting some additional information. Both the lack of benefit and the higher number of adverse events in the parenteral iron group may be related to the specific dosing schedule of ferric gluconate in this trial $(187.5 \mathrm{mg}$ of iron every 3 weeks).

The low planned total iron dose of $937.5 \mathrm{mg}$, the second lowest dose among the published trials ( 750 to $3,000 \mathrm{mg}$ ) and the lowest dose when calculated on a weekly basis $(62.5 \mathrm{mg} / \mathrm{wk})$, may have limited the potential benefit of parenteral iron supplementation. Furthermore, the iron dose that was actually administered seems to have been even lower, namely $650 \mathrm{mg}$ total iron ( $43.3 \mathrm{mg} / \mathrm{wk})$, as indicated online by Auerbach. ${ }^{10}$ In the study by Bastit et al ${ }^{4}$ that was cited by Steensma et $\mathrm{al}^{1}$ as similar to their own study, the actually delivered total iron dose was about $400 \mathrm{mg}$ higher. ${ }^{10}$ The increase of transferrin saturation (TSAT) from baseline to the end of the study that was reported by Steensma et al was substantially lower in the parenteral iron compared with the oral iron group, and even lower than in the placebo group $(+1.4 \%,+8.0 \%$, and $+1.7 \%$, respectively). This suggests that the given total dose of parenteral iron was either too low or not effectively used. In this context, Steensma et al mention that patients who were enrolled in the parenteral iron arm were more likely to withdraw consent or discontinue treatment as a result of adverse events. No information is given on how this affected the number of administered iron doses per patient.

In contrast to the low total iron dose throughout the entire study period, the single iron doses administered per treatment as ferric gluconate were rather high $(187.5 \mathrm{mg})$ and may explain the excessive number of adverse events that led to early termination of the study. In fact, this dose is $50 \%$ above the recommended dose for iron repletion with ferric gluconate in adult patients receiving hemodialysis in the United States, and therefore it is in the off-label range. Data from Ferrlecit (sanofi-aventis, Bridgewater, NJ) postmarketing reports indicate that individual doses that exceed $125 \mathrm{mg}$ of iron may be associated with a higher incidence and/or severity of adverse events. ${ }^{11}$ The high single doses of ferric gluconate in this study may have resulted in oversaturation of transferrin, formation of nontransferrinbound iron, and deposition of iron in parenchymal tissues (eg, hepatocytes) instead of in the bone marrow. Apart from the in- creased risk of inducing oxidative stress and thus causing associated adverse events, the described effects may have additionally decreased the amount of iron that was effectively available for erythropoiesis. Therefore, it would be relevant to know more about the time course of TSAT and especially the levels of TSAT 24 hours after ferric gluconate administration.

One aspect that may have affected the statistical power is the low proportion of patients who completed the study per protocol $(65 \%$ overall; $63 \%$ in the placebo and the parenteral iron arm each). Thus, given that more than one third of the patients did not complete the study, a per-protocol analysis would be informative.

In summary, the lack of response to parenteral ferric gluconate in the study by Steensma et $\mathrm{al}^{1}$ may be attributed to a suboptimal dosing regimen (ie, a low average dose but single doses that were too high) and a high proportion of dropouts rather than a lack of effectiveness per se. The superiority of parenteral iron compared with oral or no iron supplementation in terms of better hematopoietic response and less need for blood transfusions has been confirmed by two recent meta-analyses ${ }^{12,13}$ that included data from this trial as presented by Steensma et al at the 2009 meeting of the American Society of Hematology. ${ }^{14}$

\section{Matti Aapro \\ L'Institut Multidisciplinaire d'Oncologie de la Clinique de Genolier, Genolier, Switzerland}

\section{Yves Beguin}

Centre Hospitalier Universitaire of Liège and University of Liège, Liège, Belgium

\section{Gunnar Birgegård}

Uppsala University, Uppsala, Sweden

\section{Pere Gascón}

Hospital Clinic Barcelona, Barcelona, Spain

\section{Michael Hedenus}

Sundsvall Hospital, Sundsvall, Sweden

\section{Anders Österborg}

Karolinska Institutet and Karolinska Hospital, Stockholm, Sweden

\section{AUTHORS' DISCLOSURES OF POTENTIAL CONFLICTS OF INTEREST}

Although all authors completed the disclosure declaration, the following author(s) indicated a financial or other interest that is relevant to the subject matter under consideration in this article. Certain relationships marked with a " $U$ " are those for which no compensation was received; those relationships marked with a "C" were compensated. For a detailed description of the disclosure categories, or for more information about ASCO's conflict of interest policy, please refer to the Author Disclosure Declaration and the Disclosures of Potential Conflicts of Interest section in Information for Contributors.

Employment or Leadership Position: None Consultant or Advisory Role: Matti Aapro, Vifor Pharma (C), Amgen (C); Yves Beguin, Vifor Pharma (C), Amgen (C); Michael Hedenus, Vifor Pharma (U); Anders Österborg, Vifor Pharma (C) Stock Ownership: None Honoraria: Yves Beguin, Vifor Pharma, Amgen; Gunnar Birgegård, Renapharma; Pere Gascón, Vifor Pharma; Michael Hedenus, Vifor Pharma; Anders 
Österborg, Vifor Pharma Research Funding: Matti Aapro, Vifor Pharma, Amgen Expert Testimony: None Other Remuneration: None

\section{REFERENCES}

1. Steensma DP, Sloan JA, Dakhil SR, et al: Phase III, randomized study of the effects of parenteral iron, oral iron, or no iron supplementation on the erythropoietic response to darbepoetin alfa for patients with chemotherapyassociated anemia. J Clin Oncol 29:97-105, 2011

2. Auerbach $M$, Ballard $H$, Trout JR, et al: Intravenous iron optimizes the response to recombinant human erythropoietin in cancer patients with chemotherapy-related anemia: A multicenter, open-label, randomized trial. J Clin Oncol 22:1301-1307, 2004

3. Auerbach $M$, Silberstein PT, Webb RT, et al: Darbepoetin alfa 300 or 500 ug once every 3 weeks with or without intravenous iron in patients with chemotherapy-induced anemia. Am J Hematol 85:655-663, 2010

4. Bastit $L$, Vandebroek $A$, Altintas $S$, et al: Randomized, multicenter, controlled trial comparing the efficacy and safety of darbepoetin alpha administered every 3 weeks with or without intravenous iron in patients with chemotherapyinduced anemia. J Clin Oncol 26:1611-1618, 2008

5. Hedenus M, Birgegård G, Näsman $P$, et al: Addition of intravenous iron to epoetin beta increases hemoglobin response and decreases epoetin dose requirement in anemic patients with lymphoproliferative malignancies: A randomized multicenter study. Leukemia 21:627-632, 2007

6. Henry DH, Dahl NV, Auerbach $M$, et al: Intravenous ferric gluconate significantly improves response to epoetin alfa versus oral iron or no iron in anemic patients with cancer receiving chemotherapy. Oncologist 12:231-242, 2007

7. Pedrazzoli P, Farris A, Del Prete $S$, et al: Randomized trial of intravenous iron supplementation in patients with chemotherapy-related anemia without iron deficiency treated with darbepoetin alpha. J Clin Oncol 26:1619-1625 2008

8. Beguin $Y$, Maertens J, De Prijck B, et al: Darbepoetin-alfa and I.V. iron administration after autologous hematopoietic stem cell transplantation: A prospective randomized multicenter trial. Blood 112, 2008 (abstr 54)

9. Bellet RE, Ghazal H, Flam M, et al: A phase III randomized controlled study comparing iron sucrose intravenously (IV) to no iron treatment of anemia in cancer patients undergoing chemotherapy and erythropoietin stimulating agent (ESA) therapy. J Clin Oncol 25:519S, 2007 (abstr 9109)

10. Auerbach $\mathrm{M}$ : Intravenous iron failed to improve erythropoietic response in patients with chemotherapy-induced anemia. HemOnc Today, 2010. http:// www.hemonctoday.com/article.aspx? rid $=78461$

11. sanofi-aventis: Ferrlecit prescribing information. http://products.sanofi-aventis us/ferrlecit/ferrlecit.html

12. Gafter-Gvili A, Rozen-Zvi B, Vidal L, et al: Intravenous iron supplementation for the treatment of cancer-related anemia: Systematic review and metaanalysis. Blood 116:21, 2010 (abstr 4249)

13. Mhaskar $R$, Wao $H$, Kumar $A$, et al: Role of iron supplementation to erythropoiesis stimulating agents in the management of chemotherapy-induced anemia in cancer patients: A systematic review and meta-analysis. Blood 116:21, 2010 (abstr 2055)

14. Steensma D, Dakhil SR, Novotny PJ, et al: A phase III, randomized study of the effects of parenteral iron, oral iron, or no iron supplementation on the erythropoietic response to darbepoetin alfa for patients with chemotherapyassociated anemia: A study of the Mayo Clinic Cancer Research Consortium (MCCRC). Blood 114:22, 2009 (abstr 3008)

DOI: 10.1200/JCO.2011.35.3219; published online ahead of print at www.jco.org on May 2, 2011 